\title{
Aggressiveness in different presentations of cluster headache: Results from a controlled multicentric study
}

Cephalalgia

32(7) 528-536

(C) International Headache Society 2012

Reprints and permissions:

sagepub.co.uk/journalsPermissions.nav DOI: I0.1।77/0333।024I 2443336

cep.sagepub.com

\author{
Ralf Luerding ${ }^{1, *}$, Karsten Henkel ${ }^{2,3, *}$, Charly Gaul ${ }^{4,5}$, \\ Thomas Dresler ${ }^{6}$, Andrea Lindwurm ${ }^{1}$, Yvonne Paelecke-Habermann ${ }^{7}$, \\ Elke Leinisch ${ }^{1,8}$ and Tim P Jürgens ${ }^{9}$
}

\begin{abstract}
Background: The hypothalamus has been discussed as a pivotal structure for both cluster headache $(\mathrm{CH})$ and aggressiveness, but little is known about the extent of self-reported aggressiveness in patients with $\mathrm{CH}$.

Patients and methods: Twenty-six patients with chronic, 25 with active episodic and 22 with episodic $\mathrm{CH}$ outside the active period were examined interictally with a validated questionnaire quantifying factors of aggression and compared with 24 migraine patients and $3 \mathrm{I}$ headache-free volunteers.

Results: The ANOVA was significant for the subscale 'self-aggression/depression' $\left(F_{4,123}=5.77 \mathrm{I}, p<0.00 \mathrm{I}\right)$ with significant differences between chronic and episodic $\mathrm{CH}$ and healthy volunteers. No significant changes were found for other subscales and the sum scale $\left(F_{4,123}<1.421, p>0.230\right)$. Especially in the clinically most affected group of patients (chronic $\mathrm{CH}$ and active episodic $\mathrm{CH}$ ), high levels of "self-aggression/depression" correlate with higher prevalence of depressive symptoms and higher impairment measured on an emotional and functional level.

Discussion: Self-aggressive and depressive cognitions with highest scores in chronic $\mathrm{CH}$ seem to be reactive as they correlate with depressive symptoms and impairment. They should be considered as an important therapeutic target since they impair the patient's life significantly.
\end{abstract}

\section{Keywords}

Cluster headache, migraine, aggression, hypothalamus, FAF, impairment

Date received: 26 October 20II; accepted: 26 February 2012

\section{Introduction}

Cluster headache $(\mathrm{CH})$ is a severe and disabling condition characterized by excruciating unilateral pain attacks located mainly in the first trigeminal division lasting between 15 and 180 minutes (1). Attacks are accompanied by striking ipsilateral signs of parasympathetic activation and sympathetic hypoactivity (2) and lead to significant impairment $(3,4)$. As many as $90 \%$ of patients report restlessness, with visible motor symptoms such as pacing around, rocking or agitation (5). Patients often report further behavioural peculiarities ranging from complex stereotyped actions to seeking seclusion and often even refuse to see their family members. Self-inflicted injuries (such as banging their head or knocking their fists against a wall), and other

\footnotetext{
'University of Regensburg, Germany

${ }^{2}$ Kiel Headache Center, Germany

${ }^{3}$ RWTH Aachen University, Germany

${ }^{4}$ University of Halle, Germany

${ }^{5}$ University of Essen, Germany

${ }^{6}$ University of Tübingen, Germany

${ }^{7}$ University of Würzburg, Germany

${ }^{8}$ Helios Klinikum, Erfurt, Germany

'University Medical Center Hamburg-Eppendorf, Germany

*These authors contributed equally.

Corresponding author:

Tim Jürgens, Department of Systems Neuroscience, University Medical Center Hamburg-Eppendorf, Martinistrasse 52, D-20246 Hamburg, Germany

Email: t.juergens@uke.de
} 
self-aggressive respectively self-mutilating behaviour have also been reported (5-8). The rate of self-inflicted traumatic head injuries is reported to be higher in patients with $\mathrm{CH}$ than in migraine, especially for brawls (9). However, increased aggressiveness towards others has never been described as a typical finding and is mentioned only anecdotally (10-12).

Aggressiveness is a complex phenomenon and can be a correlate of other underlying disorders such as depression and pain $(13,14)$. As previous studies have reported significant psychiatric symptoms in patients with $\mathrm{CH}(4,15-17)$, higher levels of aggression - if present - could be explained by this concomitant spectrum of disease. From a pathophysiological perspective, there is good evidence for the involvement of the ventro- and dorsomedial as well as the posterior hypothalamus in the pathophysiology of aggression (18). Interventional data from animal experiments (19) and stereotactic neurosurgery of the posterior hypothalamic region in humans (20) have shown striking effects on aggressive behaviour. However, aggression cannot be reduced to the hypothalamic system alone. Extensive changes in neurotransmitter release have been described in an intricate network of areas such as the orbitofrontal and the anterior cingulate cortex (top-down control) and limbic structures, mainly the amygdala (21).

It is intriguing that neuroimaging studies have found morphological and functional changes in the posterior hypothalamus in patients with $\mathrm{CH}(22,23)$ as well, suggesting a role in the pathophysiology of $\mathrm{CH}$. This is supported by the efficacy of deep brain stimulation of the posterior hypothalamus in medically intractable CH (24-26).

It is not known whether patients with $\mathrm{CH}$ have higher levels of aggression compared to other primary headaches and healthy volunteers. In addition, it is unknown whether these changes are confined to acute attacks as a facet of intermittent hypothalamic activation or active periods (as a transient state). Alternatively, they could be constantly present as personality traits.

The aim of the study was therefore to answer the following questions in a prospective and controlled multicentre study:

1. Do patients with episodic $\mathrm{CH}$ in the active period, episodic $\mathrm{CH}$ outside the active period, or chronic $\mathrm{CH}$ show higher degrees of interictal aggression and its submodalities compared to patients with migraine and healthy volunteers?

2. Is there any relationship between aggression scores and depressive symptoms?

3 . Is there any relationship between aggression scores and headache-specific emotional and functional impairment?

\section{Patients and methods}

\section{Patients}

Headache patients were recruited at three sites in Germany (University Hospital Regensburg, University Hospital Halle, Kiel Pain Headache Center). The study focusing on aggression was part of a larger study on epidemiological and clinical aspects of CHs. Data on impairment due to headache have been published elsewhere (4). Patients were examined by an experienced headache specialist and diagnosed according to the current ICHD-II criteria for migraine without and with aura (IHS 1.1 and 1.2) and for episodic (ECH, IHS 3.1.1) and chronic cluster headache $(\mathrm{CCH}$, IHS 3.1.2.). Ninety-seven headache patients were included in total with the following subgroups: 27 patients with chronic $\mathrm{CH}, 26$ with episodic $\mathrm{CH}$ in the active period (ECHa), 22 with episodic $\mathrm{CH}$ outside the active period (ECHi) and 24 patients with migraine (MIG; 8 patients with visual aura, i.e. $33 \%$ and one from sensory aura, i.e. 4\%). Details are shown in Table 1. Thirty-one healthy volunteers without any history of primary headache disorders were recruited as a healthy control group (HC). All subjects gave written informed consent. The study was approved by the lead ethics committee of the University of Regensburg as well as the local ethics committees and was in compliance with the Declaration of Helsinki (2008).

\section{Study design}

All participants completed a face-to-face standardized interview to screen for psychiatric disorders (axis I), which is used widely in Germany (Mini-DIPS) (27). Responses to screening questions indicative for depressive syndrome were explored. Afterwards, subjects were asked to complete a questionnaire assessing modalities of aggression (FAF; see below for further information) and return it in a sealed envelope to minimize under-reporting as a modification of the sealed envelope approach (28). To ensure that data was collected interictally and to avoid loss of data patients were requested to complete all questionnaires in the clinic.

\section{Questionnaire for Measuring Factors of Aggression (FAF)}

This questionnaire reliably assesses various modalities of aggressive behaviour with 77 items. Subjects affirmed or negated FAF items in a dichotomous fashion ('Occasionally I lose my temper and become angry': yes or no) (29). The FAF evaluates five dimensions of aggressive behaviour: 1 spontaneous aggression (thoughts about aggression against others); 2 
Table I. Clinical details of patients included and results. Results on depressive symptoms have been published as part of a previous study (17)

\begin{tabular}{|c|c|c|c|c|c|}
\hline & $\mathrm{CCH}$ & $\mathrm{ECHa}$ & $\mathrm{ECHi}$ & MIG & Control \\
\hline Number & 27 & 26 & 22 & 24 & 31 \\
\hline Age (years) & 42.1 & 41.3 & 40.6 & 37.4 & 38.4 \\
\hline Gender (male:female) & 4.4:I & $5.5: 1$ & I.8:I & $\mathrm{I}: 3.8$ & I.I:I \\
\hline Duration of disease (years) & 11.4 & 12.0 & 12.6 & 13.6 & - \\
\hline Age of onset (years) & 30.6 & 29.4 & 28.2 & 23.8 & - \\
\hline Mean FAF sum score (SD) & $10.0( \pm 8.1)$ & $9.2( \pm 5.5)$ & $7.6( \pm 6.4)$ & $7.9( \pm 5.5)$ & $6.7( \pm 3.7)$ \\
\hline Depressive symptoms in the past & $15(56 \%)$ & $7(27 \%)$ & $8(36 \%)$ & $7(29 \%)$ & $6(19 \%)$ \\
\hline
\end{tabular}

$\mathrm{CCH}$ : chronic cluster headache; ECHa: episodic cluster headache in the active phase; ECHi: episodic cluster headache outside the active period; MIG: migraine; Control: healthy controls; SD: standard deviation; FAF: Questionnaire for Measuring Factors of Aggression. One subject each in the CCH and $\mathrm{ECHa}$ group did not complete the FAF questionnaire.

reactive aggression (degree of socially accepted selfassertion); 3 irritability (tolerance to frustration); 4 self-aggression/depression (dissatisfaction with own personality, self-reproach); and 5 inhibition of aggression (ability to regulate aggressive thoughts). A sum score can be calculated for the first three scales. The FAF shares some items with the Freiburg Personality Inventory and is partly based on the American Buss Durkee Hostility Inventory (30). A simple translation of the latter would not have adequately addressed cultural peculiarities for a German-speaking population.

German FAF norms were established in 630 subjects (males and females ranging from 15 to 75 years of age). The construct was validated in juvenile and adult delinquents who showed significantly increased scores for the scales 1 (spontaneous aggression), 3 (irritability), 4 (self-aggression/depression) and the sum score compared to the sample drawn from the general population. The scales do not correlate with the general intelligence quotient measured by the Wechsler Adult Intelligence Scale. The internal consistency (Cronbach's $\alpha$ ) differs between 0.61 and 0.79 for the subscales and reaches 0.85 for the sum score. The split-half reliability (Spearman-Brown) reaches 0.857 .

Adult delinquents $(n=77)$ showed significant differences in the irritability and self-aggression scales and in the sum of aggression scales in comparison to controls. The difference in self-aggression was attributed to the consequences of the imprisonment. Hampel and Selg (29) also report that the spontaneous aggression scale reached higher scores in psychiatric patients than in psychosomatic patients, lower scores in reactive aggression for both groups and higher scores for both patient groups in the irritability and the self-aggression scales. For the inhibition scale higher scores were found in psychiatric patients, whereas psychosomatic patients scored lower.
Because of this sensitivity to different aspects of aggressive behaviour, the questionnaire has been used widely in German-speaking populations in various clinical and non-clinical contexts. It was used to measure the relationship between aggression and allergic disorders (31,32), rheumatoid arthritis (33) and patients with hand dermatitis (34). Additionally, the FAF was used to correlate behaviour with specific genotypes in psychiatric patients (35-39) and in personality diagnostics in Austrian (40) and Swiss psychiatric patients (41).

\section{Headache Disability Inventory (HDI)}

All participants completed the German adaptation of the 25-item Henry Ford Hospital Headache Disability Inventory (HDI) $(42,43)$ with a 'total' score and two subscores (EMOTION with 13 items for the influence of headache on mood) and FUNCTION (12 items to detect restrictions in activities of daily living). Detailed results can be found elsewhere (4).

\section{Statistics}

Data were analysed with SPSS 18 for Windows (SPSS; Chicago, IL, USA). The scores of the six subscales and the sum scale were entered separately in univariate analyses of variance (ANOVAs) with the between-factor 'group'. If variance homogeneity was violated, effects were verified by means of non-parametric KruskalWallis H-test. Post hoc tests were used to further investigate significant main effects. Bonferroni correction was used to correct for multiple testing (10 comparisons required $p_{\text {uncorrected }}<0.005$ to achieve global $p<0.05$ ). When necessary for detailed understanding of results non-corrected least significant differences are reported (i.e. $p_{\text {uncorrected }}<0.05$ ). 


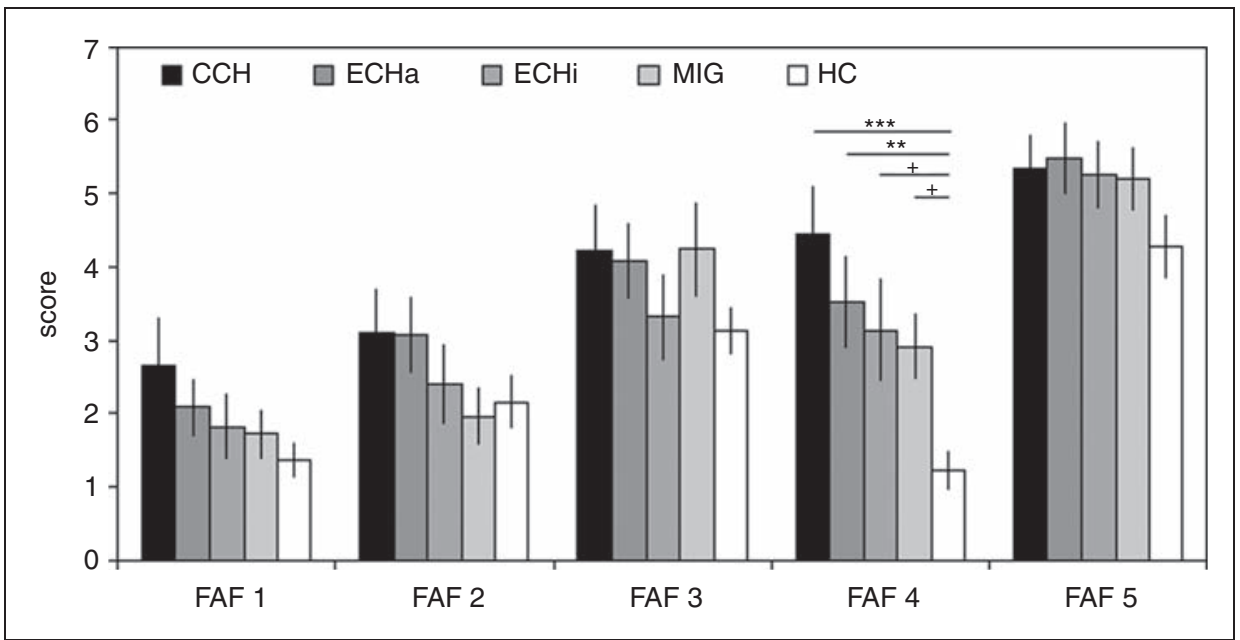

Figure I. Mean FAF subscores given for the different groups (cluster headache, migraine, healthy volunteers). Whiskers represent standard error of the mean. Results of Bonferroni corrected post hoc $t$-tests are given as follows: $*^{* *}<0.001, *^{*}<0.01,{ }^{+}<0.10$ (onetailed).

FAF: Questionnaire for Measuring Factors of Aggression; FAF I: spontaneous aggression (thoughts about aggression against others); FAF 2: reactive aggression (degree of socially accepted self-assertion); FAF 3: irritability (tolerance to frustration); FAF 4: selfaggression/depression (dissatisfaction with own personality, self-reproach); FAF 5: inhibition of aggression (ability to regulate aggressive thoughts). $\mathrm{CCH}$ : chronic cluster headache; $\mathrm{ECHa}$ : episodic cluster headache in the active phase; ECHi: episodic cluster headache outside the active period; MIG: migraine; HC: healthy controls.

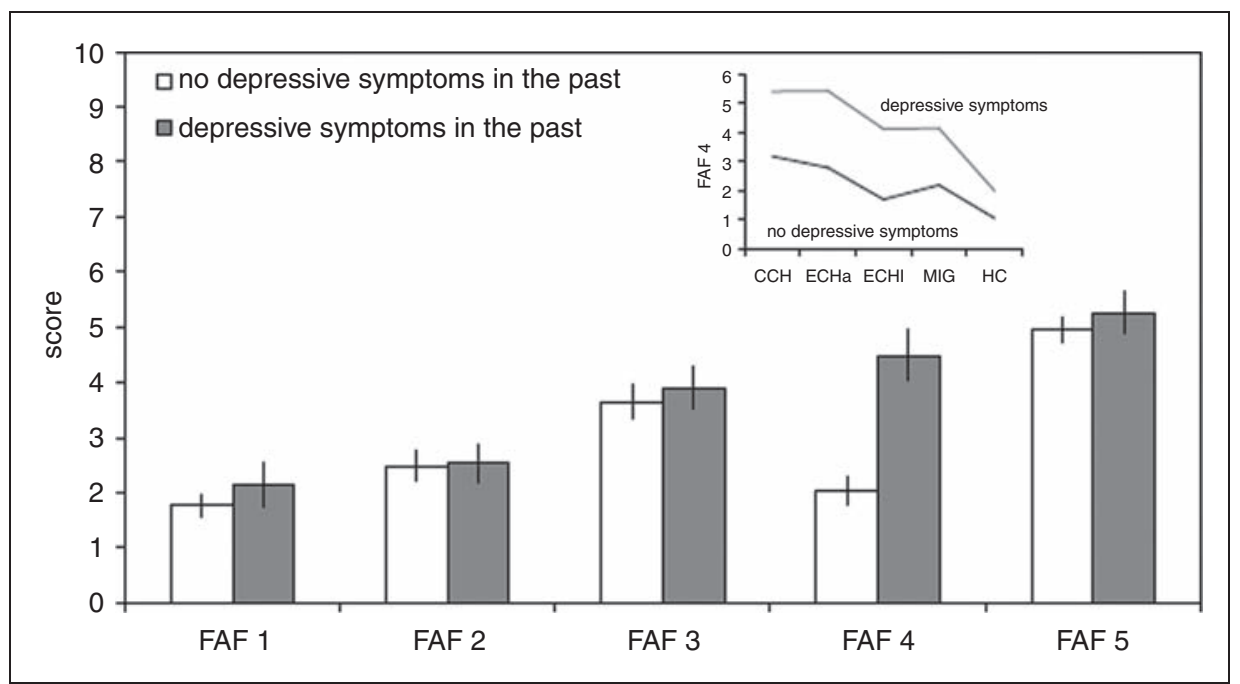

Figure 2. Mean FAF subscores in all participants subject to depressive symptoms in the past. Occurrence of depressive symptoms for subscale FAF4 is indicated in the small additional figure in a dichotomous fashion (depressive symptoms present in the past or not) to illustrate comparable effects across groups. Whiskers represent standard error of the mean.

FAF: Questionnaire for Measuring Factors of Aggression; FAF I: spontaneous aggression (thoughts about aggression against others); FAF 2: reactive aggression (degree of socially accepted self-assertion); FAF 3: irritability (tolerance to frustration); FAF 4: selfaggression/depression (dissatisfaction with own personality, self-reproach); FAF 5: inhibition of aggression (ability to regulate aggressive thoughts). $\mathrm{CCH}$ : chronic cluster headache; $\mathrm{ECHa}$ : episodic cluster headache in the active phase; ECHi: episodic cluster headache outside the active period; MIG: migraine; HC: healthy controls.

Further analyses tested if revealed that a linear model would fit best to detect a polynomial contrast despite non-significant main effects (such as a linear increase or decrease in a measure from the chronic
$\mathrm{CH}$ patients over other patient groups to healthy controls). We thus applied a polynomial linear contrast weighting groups $\left(\begin{array}{lllll}2 & 1 & 0 & -1 & -2\end{array}\right)$ in the expected order $(\mathrm{CCH}$, ECHa, ECHi, MIG, HC). As we had 
hypotheses about the order of groups (highest values in the $\mathrm{CCH}$ group, lowest values in the $\mathrm{HC}$ group), we applied one-tailed testing for post hoc comparisons.

To investigate any association of the self-aggression/ depression scale with depressive symptoms we tested whether subjects reporting previous depressive symptoms had increased scores on this scale by means of an ANOVA.

Bivariate correlations were calculated to examine a potential relation between the degree of impairment and the extent of FAF4 scores for self-aggression/ depression (Bonferroni-corrected). Pairwise comparisons between the presence of depressive symptoms in the past and total scores on the HDI were calculated by means of Mann-Whitney U-tests (non-parametric tests were used because variables were unevenly distributed).

\section{Results}

Clinical data for the headache patients and the controls are shown in Table 1. FAF data were incomplete and thus regarded as missing for one chronic and one $\mathrm{CH}$ patient in the active episode. Results for FAF total score are given in Table 1, for all subscores in Figure 1.

\section{FAF scores}

The ANOVA proved to be significant for the selfaggression/depression subscale $\quad\left(F_{4,123}=5.771\right.$, $p<0.001$ ), but not for the other subscales and the sum scale, respectively $\left(F_{4,123}<1.421, p>0.230\right)$. Due to violation of variance homogeneity for some scales, the Kruskal-Wallis H-test was used, the results of which matched those from the ANOVA. Bonferronicorrected post hoc $t$-tests revealed that for self-aggression the $\mathrm{HC}$ group displayed significantly lower values compared to $\mathrm{CCH}(p<0.001)$ and $\mathrm{ECHa}(p=0.007)$, and marginally lower values compared to the ECHi $(p=0.052)$ and MIG groups $(p=0.099)$. No significant differences between the headache patient groups could be found. At an uncorrected level, $\mathrm{CCH}$ patients also had significantly higher values than the ECHi and MIG groups (see Figure 1).

A significant linear trend indicating decreasing levels of self-aggression/depression from $\mathrm{CCH}$ to $\mathrm{HC}$ was found $\left(F_{1,123}=20.997, p<0.001\right.$, Figure 1). Although main effects for spontaneous and reactive aggression and for the sum scale did not reach significance, linear trends were significant for these three scales $\left(F_{1,123}>4.246, p<0.041\right)$. At an uncorrected level, post hoc $t$-tests reached significant differences (see Figure 1). Namely, for spontaneous aggression $\mathrm{CCH}$ had higher values than the $\mathrm{HC}(p=0.012)$, for reactive aggression patients with $\mathrm{CCH}$ and ECHa had higher
Table 2. Correlation of FAF 4 scores (self-aggression/depression) with impairment scores in the German adaption of the Headache Disability Inventory. Pearson's correlation coefficient is reported with $p$-values in parentheses. Results that remain statistically significant $(p<0.05)$ after Bonferroni's correction are printed in bold

\begin{tabular}{lccc}
\hline $\begin{array}{l}\text { Correlation of FAF4 } \\
\text { scores with }\end{array}$ & HDI total & HDI emotion & HDI function \\
\hline $\mathrm{CCH}$ & 0.629 & 0.677 & 0.492 \\
& $(\boldsymbol{p}=\mathbf{0 . 0 0 I})$ & $(\boldsymbol{p}<\mathbf{0 . 0 0 I})$ & $(\boldsymbol{p}=\mathbf{0 . 0 I I})$ \\
ECHa & 0.654 & 0.703 & 0.524 \\
& $(\boldsymbol{p}=\mathbf{0 . 0 0 I})$ & $(\boldsymbol{p}<\mathbf{0 . 0 0 I})$ & $(\boldsymbol{p}=\mathbf{0 . 0 0 9 )}$ \\
ECHi & 0.453 & 0.465 & 0.410 \\
& $(p=0.039)$ & $(p=0.034)$ & $(p=0.065)$ \\
MIG & 0.436 & 0.474 & 0.328 \\
& $(p=0.033)$ & $(p=0.019)$ & $(p=0.117)$ \\
Control & 0.054 & 0.055 & -0.019 \\
& $(p=0.817)$ & $(p=0.813)$ & $(p=0.934)$ \\
\hline
\end{tabular}

$\mathrm{CCH}$ : chronic cluster headache; $\mathrm{ECH}$ : episodic cluster headache in the active phase; ECHi: episodic cluster headache outside the active period; MIG: migraine; Control: healthy controls; FAF: Questionnaire for Measuring Factors of Aggression; HDI: Headache Disability Inventory.

values than the MIG group $(p<0.05)$, and for the sum scale aggression $\mathrm{CCH}$ had higher values than the HC group $(p=0.018)$.

\section{Relationship with depressive symptoms}

A $2 \times 5$ ANOVA was performed with the factors 'depressive symptoms' (depressed in the past vs. not depressed in the past) and 'group' (active and inactive episodic and chronic $\mathrm{CH}$, migraine and healthy controls) for each of the five FAF subscores and the sum score to explore a significant main effect of 'depressive symptoms'. For the dependent variable self-aggression/ depression the analysis revealed a significant main effect for 'depressive symptoms' $\left(F_{1,113}=17.257, p<0.001\right)$ and group $\left(F_{4,113}=4.201, p=0.003\right)$ while the interaction term proved to be non-significant $\left(F_{1,113}=0.346, p=0.846\right)$. That is, all patient groups and the $\mathrm{HC}$ group displayed a pattern of higher scores in self-aggression/depression when reporting previous depressive symptoms. The group effect replicates the general finding mentioned above. No significant main effects for 'depressive symptoms' were found in the other FAF subscales and the sum scale (Figure 2).

\section{Relationship with impairment}

Higher levels of FAF4 scores (self-aggression/depression) were associated with more severe impairment measured by the German adaptation of the HDI. 
Table 3. HDI scores depending on depressive symptoms in the investigated groups. Statistics refer to results of non-parametric Mann-Whitney U-tests, as distribution of subjects retrospectively reporting depression within the groups was uneven. For some controls, HDI scores were not available. Significant results $(p<0.05)$ are printed in bold

\begin{tabular}{|c|c|c|c|}
\hline $\begin{array}{l}\text { HDI total } \\
\text { score }\end{array}$ & $\begin{array}{l}\text { No depressive } \\
\text { symptoms in } \\
\text { the past }\end{array}$ & $\begin{array}{l}\text { Depressive } \\
\text { symptoms } \\
\text { in the past }\end{array}$ & Statistics \\
\hline $\mathrm{CCH}$ & $\begin{array}{c}52.00 \pm 24.24 \\
(n=12)\end{array}$ & $\begin{array}{c}70.93 \pm 19.15 \\
(n=15)\end{array}$ & $p=0.037$ \\
\hline $\mathrm{ECHa}$ & $\begin{array}{c}50.44 \pm 17.66 \\
(n=18)\end{array}$ & $\begin{array}{c}82.57 \pm 14.13 \\
(n=7)\end{array}$ & $p=0.001$ \\
\hline $\mathrm{ECHi}$ & $\begin{array}{c}37.40 \pm 20.91 \\
(n=10)\end{array}$ & $\begin{array}{c}48.29 \pm 33.22 \\
(n=7)\end{array}$ & $p=0.536$ \\
\hline MIG & $\begin{array}{c}41.19 \pm 20.21 \\
(n=16)\end{array}$ & $\begin{array}{c}40.86 \pm 18.72 \\
(n=7)\end{array}$ & $p=0.671$ \\
\hline Control & $\begin{array}{c}6.06 \pm 9.36 \\
(n=17)\end{array}$ & $\begin{array}{c}1.50 \pm 1.92 \\
(n=4)\end{array}$ & $p=0.275$ \\
\hline
\end{tabular}

$\mathrm{CCH}$ : chronic cluster headache; $\mathrm{ECHa}$ : episodic cluster headache in the active phase; ECHi: episodic cluster headache outside the active period; MIG: migraine; Control: healthy controls; FAF: Questionnaire for Measuring Factors of Aggression; HDI: Headache Disability Inventory.

In the most severely affected groups $(\mathrm{CCH}$ and $\mathrm{ECHa}$ ) effects were most pronounced (Table 2) and remained significant after correction for multiple testing.

\section{Relationship of depressive symptoms and impairment}

Participants from the $\mathrm{CCH}$ and the ECHa groups, who reported depressive symptoms in the past, had significantly higher levels of impairment (total score) in the German adaptation of the HDI. In the other groups, mean values differed numerically but did not reach significance (Table 3).

\section{Discussion}

The ANOVA proved to be significant for the selfaggression/depression subscale but not for the other subscales and the sum scale. Post hoc tests revealed significantly increased self-aggression scores for patients with chronic $\mathrm{CH}$ and episodic $\mathrm{CH}$ in the active period compared to healthy volunteers, but not among the headache groups. Participants who reported being depressed in the past showed an increase in the FAF self-aggression/depression subscore. Additionally, the degree of self-aggression/depression was associated with headache-specific impairment, especially in patients with chronic and active episodic $\mathrm{CH}$. This, â history of depression coincided with greater impairment.

\section{Self-aggressive cognition, depressive symptoms and impairment}

The 'self-aggression/depression' domain, as measured in the FAF, represents feelings of dissatisfaction with one's own personality, tendencies of self-reproach and depressive symptoms. Self-aggression in terms of physical aggression directed against oneself leading to selfmutilation or self-inflicted injuries are not covered. In a previous study (4) in the same sample, the lifetime prevalence of depressive symptoms was found to be highest in patients with chronic $\mathrm{CH}$, followed by those with episodic $\mathrm{CH}$ and migraine and was shown lowest in healthy controls. Impairment scores showed a similar distribution, with highest scores among patients with active $\mathrm{CH}$, lower scores in the ECHi and MIG groups and lowest scores in healthy controls. We could show that patients with active $\mathrm{CH}$ and depressive symptoms in the past suffered from significantly higher impairment (as confirmed with the total score of the HDI) than patients with inactive $\mathrm{CH}$, migraine or healthy controls. These results are in line with studies showing elevated incidence of depression in $\mathrm{CH}$ patients $(15,17)$. Increased disability was associated with increased depression scores (17).

Our findings corroborate these data as participants reporting depressive symptoms in the past also displayed increased scores in the self-aggression/depression domain only. In line with these observations, a positive relationship was found between levels of selfaggression and scores on the German adaptation of the HDI (total, emotion and function). Headache patients with a history of depressive symptoms showed higher scores of self-reproach and dissatisfaction than those without symptoms of affective distress in the past; these were most pronounced for patients in the $\mathrm{CCH}$ and the ECHa groups. These results support the notion that severely affected patients with $\mathrm{CH}$ suffer from a significant and complex psychosocial impairment, as shown in other studies (see (4) for further review). The factors 'self-aggression', 'depressive symptoms' and 'impairment' correlate with each other and it is tempting to propose a common pathophysiological ground.

Higher levels of self-aggression/depression could at least be partly explained by higher pain densities in patients with $\mathrm{CH}$. However, it seems noteworthy that patients with inactive $\mathrm{ECH}$, who have a significantly lower current pain density than migraine patients, had higher levels of self-aggression/depression than migraine patients. This would argue against pure pain-related effects. 
It is conceivable that the observed psychiatric comorbidity could be one reason for increased aggression (14), as found in other studies which focused mainly on delinquents, patients with personality disorders and patients with suicidal tendencies (35-41). Interestingly, in our study population patients with $\mathrm{CCH}$ frequently reported suicidal tendencies in the past. However, we could only find increased scores of internalizing aggressive behaviour that is more associated with depressive symptoms/self-reproach, whereas increased externalizing aggressive behaviour could not be found. Therefore, any causal attribution would be speculative and is far beyond the scope of our study.

\section{Role of the hypothalamus in $\mathrm{CH}$ and aggression}

Several lines of evidence point to the hypothalamus as a crucial pathophysiological structure in patients with CHs. Neuroimaging $(22,23)$ and studies on hormonal regulation suggest hypothalamic involvement $(44,45)$ and consequently deep brain stimulation of the posterior hypothalamus was successfully established in refractory $\mathrm{CH}(25,26,46-49)$. Interestingly, the posteromedial hypothalamus had also been a target for stereotactic lesions not only in intractable pain (50) but also in aggressive behaviour (20). Accidental intraoperative stimulation of the adjacent 'triangle of Sano' (region between the posterior hypothalamic area medially and the medial subthalamic nucleus laterally) led to an outburst of previously unknown aggressive behaviour in a patient with Parkinson's disease (51). In animal experiments, various parts of the hypothalamus were shown to be involved in different facets of aggression $(18,19,52,53)$. Accordingly, in humans aggressive behaviour can be ameliorated by stimulation of the posterior hypothalamus $(54,55)$.

Although these studies suggest a potential dual role of the posterior hypothalamus in both aggression and $\mathrm{CH}$, our results cannot support such a hypothesis.

\section{Aggression in migraine}

In the present study, no significant differences were found for factors of aggression in migraine patients compared with $\mathrm{CH}$ patients and healthy controls apart from self-aggression/depression. Self-aggression in migraine patients compared to healthy controls showed a trend towards higher scores. Likewise, the positive correlation between self-aggression and impairment reached significance on an uncorrected level for the total score and the emotion subscale on the HDI. However, a history of depressive symptoms had no influence on the level of self-aggression.
Limited data is available for aggression in migraine. Although not statistically significant, the low level of inhibition of aggression in migraine patients was comparable to that of $\mathrm{CH}$ patients. This is supported by studies in adults, adolescents and children with migraine, which have shown a reduced ability to repress aggression and anger (56-58). Irritability was highest on the day before an attack (46\%) and still present in $21 \%$ of migraine patients interictally (59).

Our findings of increased self-aggression in migraine patients are generally in line with the changes observed for patients with active $\mathrm{CH}$, however they were less pronounced. Increased levels of depression coincide with increased self-aggression. Depression has been extensively reported in migraine (60), but there is only limited data comparing the prevalence of depression in different primary headaches. As reported elsewhere (4), in our study population a history of depressive symptoms could be found most frequently in patients with $\mathrm{CCH}$, while those with active and inactive episodic $\mathrm{CH}$ reported depressive symptoms as frequently as those with migraine. Gesztelyi and co-workers found that migraine patients had even higher median scores in Beck's Depression Inventory (median: 8) than patients with $\mathrm{CH}$ (median: 5) and healthy volunteers (median: 2) with highest disability in the $\mathrm{CH}$ group followed by the migraine group. However, as a limitation group sizes differed strongly (61). Although a history of depressive symptoms was not associated with higher impairment in our study, quality of life in patients with migraine was lower than in healthy controls and higher than in patients with active $\mathrm{CH}$ in another study (62).

\section{Limitations}

Because of the nature of our study, aggression was only examined interictally. Therefore, we cannot rule out that ictal changes within an acute attack were missed. However, it did not seem feasible to ask the patients with active $\mathrm{CH}$ to complete a questionnaire during an attack. In future studies, interviewing partners of patients should also be considered and eventually searching for signs of aggression on a physical level, in contrast to the cognitive approach with specific questionnaires in this study.

\section{Conclusion}

Our findings did not corroborate significantly increased levels of aggression other than self-aggression in the context of self-reproach as a correlate of depression in patients with active $\mathrm{CH}$. In line with previous studies, self-aggression correlated with emotional and functional measures of impairment with highest disability in the clinically most affected groups with active $\mathrm{CH}$. Likewise, we 
could substantiate a close relationship between reporting of depressive symptoms and headache-specific impairment. As our study was not designed to detect a causal interrelationship between these three dimensions, further studies will have to address this issue.

As we could not corroborate any significant effect beyond self-aggression, our data do not support a dual role of the hypothalamus in the generation of both aggression and $\mathrm{CH}$. As a clinical consequence, self-aggression in the context of depression should be clinically monitored and therapeutically targeted.

\section{Acknowledgements}

This study was conducted by members of the DMKG (German Migraine and Headache Society) network of young researchers.

\section{Funding}

This research received no specific grant from any funding agency in the public, commercial, or not-for-profit sectors.

\section{Conflict of interest}

RL, TD, YPH, AL and EL: no conflict of interest. KH: has received honoraria from Gruenenthal. CG: has received research grants and honoraria from the Roux-Program of the University of Halle-Wittenberg, MSD, Berlin Chemie, Medtronic, Allergan and Böhringer Ingelheim. TPJ: has received grants and honoraria from MSD.

\section{References}

1. Headache Classification Subcommittee of the International Headache Society. The International Classification of Headache Disorders: 2nd edition. Cephalalgia 2004; 24(Suppl 1): 9-160.

2. Bahra A, May A and Goadsby PJ. Cluster headache: a prospective clinical study with diagnostic implications. Neurology 2002; 58: 354-361.

3. Jensen RM, Lyngberg A and Jensen RH. Burden of cluster headache. Cephalalgia 2007; 27: 535-541.

4. Jürgens TP, Gaul C, Lindwurm A, et al. Impairment in episodic and chronic cluster headache. Cephalalgia 2011; 31: 671-682.

5. Torelli P and Manzoni GC. Behavior during cluster headache. Curr Pain Headache Rep 2005; 9: 113-119.

6. Torelli P and Manzoni GC. Pain and behaviour in cluster headache. A prospective study and review of the literature. Funct Neurol 2003; 18: 205-210.

7. Attanasio A, D'Amico D, Frediani F, et al. Trigeminal autonomic cephalgia with periorbital ecchymosis, ocular hemorrhage, hypertension and behavioral alterations. Pain 2000; 88: 109-112.

8. Blau JN. Behaviour during a cluster headache. Lancet 1993; 342: 723-725.

9. Lambru G, Castellini P, Manzoni GC, et al. Mode of occurrence of traumatic head injuries in male patients with cluster headache or migraine: Is there a connection with lifestyle? Cephalalgia 2010; 30: 1502-1508.
10. Kudrow L. Cluster headache: diagnosis and management. Headache 1979; 19: 142-150.

11. Loder E and Loder J. Medicolegal issues in cluster headache. Curr Pain Headache Rep 2004; 8: 147-156.

12. Rogado AZ and Graham JR. Through a glass darkly. Headache 1979; 19: 58-62.

13. Anderson KB, Anderson CA, Dill KE, et al. The interactive relations between trait hostility, pain, and aggressive thoughts. Aggress Behav 1998; 24: 161-171.

14. Wiersma JE, van Oppen P, van Schaik DJ, et al. Psychological characteristics of chronic depression: a longitudinal cohort study. J Clin Psychiatry 2011; 72: 288-294.

15. Donnet A, Lanteri-Minet M, Guegan-Massardier E, et al. Chronic cluster headache: a French clinical descriptive study. J Neurol Neurosurg Psychiatry 2007; 78: 1354-1358.

16. Jorge RE, Leston JE, Arndt S, et al. Cluster headaches: association with anxiety disorders and memory deficits. Neurology 1999; 53: 543-547.

17. Seifert CL, Valet M, Pfaffenrath V, et al. Neurometabolic correlates of depression and disability in episodic cluster headache. J Neurol 2011; 258: 123-131.

18. Canteras NS. The medial hypothalamic defensive system: hodological organization and functional implications. Pharmacol Biochem Behav 2002; 71: 481-491.

19. Yin TH and Chen YC. Localization of inhibitory mechanisms to aggressiveness in the medial hypothalamus. Chin J Physiol 1978; 22: 155-164.

20. Sano K and Mayanagi Y. Posteromedial hypothalamotomy in the treatment of violent, aggressive behaviour. Acta Neurochir Suppl (Wien) 1988; 44: 145-151.

21. Siever LJ. Neurobiology of aggression and violence. Am J Psychiatry 2008; 165: 429-442.

22. May A, Ashburner J, Buchel C, et al. Correlation between structural and functional changes in brain in an idiopathic headache syndrome. Nat Med 1999; 5: 836-838.

23. May A, Bahra A, Buchel C, et al. Hypothalamic activation in cluster headache attacks. Lancet 1998; 352: 275-278.

24. Leone M. Deep brain stimulation in headache. Lancet Neurol 2006; 5: 873-877.

25. Leone M, Franzini A, Broggi G, et al. Hypothalamic stimulation for intractable cluster headache: long-term experience. Neurology 2006; 67: 150-152.

26. Schoenen J, Di Clemente L, Vandenheede M, et al. Hypothalamic stimulation in chronic cluster headache: a pilot study of efficacy and mode of action. Brain 2005; 128: 940-947.

27. Margraf J. Mini-DIPS: Diagnostisches Kurz-Interview bei psychischen Störungen. Berlin: Springer, 1994.

28. McAllister I and Makkai T. Correcting for the underreporting of drug use in opinion surveys. Int J Addict 1991; 26: 945-961.

29. Hampel R and Selg H. FAF - Fragebogen zur Erfassung von Aggressivitätsfaktoren. Handanweisung. Göttingen: Hogrefe, 1998.

30. Buss AH and Durkee A. An inventory for assessing different kinds of hostility. J Consult Psychol 1957; 21: 343-349. 
31. Matussek P, Agerer D and Seibt G. Aggression and allergic disorder in depressives. J Psychosom Res 1984; 28 : 205-211.

32. Matussek P, Agerer D and Seibt G. Aggression in depressives and psoriatics. Psychother Psychosom 1985; 43: 120-125.

33. Kohler T and Boelicke T. [Do patients with rheumatoid arthritis suppress anger and aggression?]. Psychother Psychosom Med Psychol 2000; 50: 157-160.

34. Niemeier V, Nippesen M, Kupfer J, et al. Psychological factors associated with hand dermatoses: which subgroup needs additional psychological care? Br J Dermatol 2002; 146: 1031-1037.

35. Giegling I, Hartmann AM, Moller HJ, et al. Anger- and aggression-related traits are associated with polymorphisms in the 5-HT-2A gene. J Affect Disord 2006; 96: $75-81$.

36. Giegling I, Olgiati P, Hartmann AM, et al. Personality and attempted suicide. Analysis of anger, aggression and impulsivity. J Psychiatr Res 2009; 43: 1262-1271.

37. Giegling I, Rujescu D, Mandelli L, et al. Tachykinin receptor 1 variants associated with aggression in suicidal behavior. Am J Med Genet B Neuropsychiatr Genet 2007; 144B: $757-761$.

38. Giegling I, Rujescu D, Mandelli L, et al. Estrogen receptor gene 1 variants are not associated with suicidal behavior. Psychiatry Res 2008; 160: 1-7.

39. Gietl A, Giegling I, Hartmann AM, et al. ABCG1 gene variants in suicidal behavior and aggression-related traits. Eur Neuropsychopharmacol 2007; 17: 410-416.

40. Ille R, Lahousen T, Rous F, et al. [Personality profile and psychic deviations in offenders examined for psychiatricforensic appraisal]. Nervenarzt 2005; 76: 52-60.

41. de Tribolet-Hardy F, Vohs K, Domes G, et al. [Violent offenders with or without antisocial personality disorder. A comparison]. Nervenarzt 2011; 82: 43-49.

42. Jacobson GP, Ramadan NM, Aggarwal SK, et al. The Henry Ford Hospital Headache Disability Inventory (HDI). Neurology 1994; 44: 837-842.

43. Bauer B, Evers S, Gralow I, et al. [Psychosocial handicap due to chronic headaches. Evaluation of the inventory of disabilities caused by headache]. Nervenarzt 1999; 70: $522-529$.

44. Leone $\mathrm{M}$ and Bussone $\mathrm{G}$. A review of hormonal findings in cluster headache. Evidence for hypothalamic involvement. Cephalalgia 1993; 13: 309-317.

45. Pringsheim T. Cluster headache: evidence for a disorder of circadian rhythm and hypothalamic function. Can J Neurol Sci 2002; 29: 33-40.

46. Leone M, Franzini A, Broggi G, et al. Long-term followup of bilateral hypothalamic stimulation for intractable cluster headache. Brain 2004; 127: 2259-2264.

47. Leone M, Franzini A and Bussone G. Stereotactic stimulation of posterior hypothalamic gray matter in a patient with intractable cluster headache. N Engl J Med 2001; 345: 1428-1429.

48. Leone M, Proietti Cecchini A, Franzini A, et al. Lessons from 8 years' experience of hypothalamic stimulation in cluster headache. Cephalalgia 2008; 28: 789-797.

49. Fontaine D, Lazorthes Y, Mertens P, et al. Safety and efficacy of deep brain stimulation in refractory cluster headache: a randomized placebo-controlled doubleblind trial followed by a 1-year open extension. $J$ Headache Pain 2010; 11: 23-31.

50. Sano K, Sekino H, Hashimoto I, et al. Posteromedial hypothalamotomy in the treatment of tractable pain. Confin Neurol 1975; 37: 285-290.

51. Bejjani BP, Houeto JL, Hariz M, et al. Aggressive behavior induced by intraoperative stimulation in the triangle of Sano. Neurology 2002; 59: 1425-1427.

52. Lin D, Boyle MP, Dollar P, et al. Functional identification of an aggression locus in the mouse hypothalamus. Nature 2011; 470: 221-226.

53. Kruk MR, Van der Poel AM, Meelis W, et al. Discriminant analysis of the localization of aggression-inducing electrode placements in the hypothalamus of male rats. Brain Res 1983; 260: 61-79.

54. Franzini A, Marras C, Ferroli P, et al. Stimulation of the posterior hypothalamus for medically intractable impulsive and violent behavior. Stereotact Funct Neurosurg 2005; 83: 63-66.

55. Kuhn J, Lenartz D, Mai JK, et al. Disappearance of selfaggressive behavior in a brain-injured patient after deep brain stimulation of the hypothalamus: technical case report. Neurosurgery 2008; 62: E1182; discussion E.

56. Furmanski AR. Dynamic concepts of migraine; a character study of one hundred patients. AMA Arch Neurol Psychiatry 1952; 67: 23-31.

57. Abbate-Daga G, Fassino S, Lo Giudice R, et al. Anger, depression and personality dimensions in patients with migraine without aura. Psychother Psychosom 2007; 76: 122-128.

58. Lanzi G, Zambrino CA, Ferrari-Ginevra O, et al. Personality traits in childhood and adolescent headache. Cephalalgia 2001; 21: 53-60.

59. Quintela E, Castillo J, Munoz P, et al. Premonitory and resolution symptoms in migraine: a prospective study in 100 unselected patients. Cephalalgia 2006; 26: 1051-1060.

60. Breslau N, Lipton RB, Stewart WF, et al. Comorbidity of migraine and depression: investigating potential etiology and prognosis. Neurology 2003; 60: 1308-1312.

61. Gesztelyi G and Bereczki D. Disability is the major determinant of the severity of depressive symptoms in primary headaches but not in low back pain. Cephalalgia 2005; 25: 598-604.

62. Ertsey C, Manhalter N, Bozsik G, et al. Health-related and condition-specific quality of life in episodic cluster headache. Cephalalgia 2004; 24: 188-196. 